University for Business and Technology in Kosovo

UBT Knowledge Center

UBT International Conference

2017 UBT International Conference

Oct 28th, 2:00 PM - 3:30 PM

\title{
Learning Management Systems in Higher Education
}

\author{
Romina Agaçi \\ University of Vlorë, romina20agaci@gmail.com
}

Follow this and additional works at: https://knowledgecenter.ubt-uni.net/conference

Part of the Databases and Information Systems Commons, and the Information Security Commons

\section{Recommended Citation}

Agaçi, Romina, "Learning Management Systems in Higher Education" (2017). UBT International Conference. 190.

https://knowledgecenter.ubt-uni.net/conference/2017/all-events/190

This Event is brought to you for free and open access by the Publication and Journals at UBT Knowledge Center. It has been accepted for inclusion in UBT International Conference by an authorized administrator of UBT Knowledge Center. For more information, please contact knowledge.center@ubt-uni.net. 


\title{
Learning Management Systems in Higher Education
}

\author{
Romina Agaçi \\ Department of Computer Science, \\ University of Vlora "Ismail Qemali", Albania \\ romina20agaci@gmail.com
}

\begin{abstract}
Learning Management Systems (LMSs) are improving learning processes and are widely used in higher education institutions. There are available various types of LMSs used by pedagogues to manage eLearning and to deliver course materials to students.Nowadays, LMSs have become essential tools that affect the quality of learning and teaching in higher education. In this article, we introduce LMSs and we choose Moodle as a tool to present an information system that is used in ouruniversity.Moodle is an online learning environment that supports classroom teaching. We will focus on the advantages of LMSs and why we choose Moodle as the best open source LMSs.
\end{abstract}

Keywords: LMSs, eLearning, Moodle, information system, open source

\section{Introduction}

E-Learning is considered a system that enables the learning process anywhere and anytime and uses electronic communication. Students can learn anywhere with a computer or mobile device and internet connection. There are a number of e-learning systems or methods that enable the delivery of courses, such as Learning Management Systems, that are widely used in universities. They are not intended to substitute face-to-face learning, but to improve it.

Learning Management Systems (LMSs) are computer systems that distribute course materials, manage online courses and allow collaboration between students and pedagogues. Such systems can be labeled in other terms, for example, CMS stands for Course Management System, LCMS stands for LearningContent Management System, VLS stands for Virtual Learning System and VLE stands for Virtual Learning Environment [1]. Through an LMS we can manage any aspect of the course starting from student enrollment, delivery of course materials to students, acceptance of the assignments and their grading. LMSs support fully online courses [2], as well as several hybrid forms, such as blended learning, a combination of online and face-to-face learning.

LMSs can be divided into three fundamental groups: commercial or proprietary, open-source and cloud-based system. Depending on your budget and needs you can choose one of these types of systems and use it to achieve the right level of student education. We choose Moodle among others to help students, to engage, stimulate and motivate them in exploring classroom materials and to enhance collaboration between students and instructors.

\section{Features and benefits of LMSs}

LMS plays an important role in higher education and it offers many functionality but we can mention two of its main functions: it serves as a communication tool and is considered a 
content provider (organizer). However, we will summarize the overall functions of an LMS and see how it is designed.LMS is used by three main categories: administrator, teachers and students [3]. Based on these categories and the functions of an LMS are shared among these members. The following table specifies the functions of each of them.

Table 6. Functions of three categories

\begin{tabular}{|c|c|c|}
\hline Student & Teacher & Administrator \\
\hline Login (Registration) & Login (Registration) & Login (Registration) \\
\hline Enroll Courses & Enroll Students & $\begin{array}{l}\text { Administer Course } \\
\text { Registration }\end{array}$ \\
\hline View/Select Courses & View/Select/Rename Courses & Add Courses \\
\hline Download Resources & Upload Resources & $\begin{array}{c}\text { Track Students\& } \text { Teacher } \\
\text { Registration/Access }\end{array}$ \\
\hline Participate in Forums/Chats & Post Forums/Chats & Manage the whole system \\
\hline $\begin{array}{c}\text { Take Quizzes/Tests and } \\
\text { Assignments/ } \\
\text { Announcements }\end{array}$ & $\begin{array}{c}\text { Post Quizzes/Tests and } \\
\text { Assignments/ Announcements }\end{array}$ & \\
\hline Upload Assignments & Download Assignments & \\
\hline \multirow[t]{4}{*}{$\begin{array}{c}\text { Evaluation/Grade the } \\
\text { Courses }\end{array}$} & $\begin{array}{c}\text { Evaluation/Grade Tests and } \\
\text { Assignments }\end{array}$ & \\
\hline & Curriculum Planning & \\
\hline & Manage Reports Generation & \\
\hline & $\begin{array}{c}\text { Provide Course } \\
\text { Scheduling/Administration }\end{array}$ & \\
\hline
\end{tabular}

LMSs are beneficial in organizing and presenting digital content. They enable communication tools such as e-mail, forums, announcement posts and collaborative tools such as glossary, wiki, blog. This promotes student collaboration and encourages interaction to join and share knowledge between them. LMSs offer the variety learning modes. They support different formats of content, for instance text, video and multimedia. So students can learn the content through articles, audio, video, photos and simulations. LMSs provide an aesthetically pleasing graphical user interface so that users can easily understand the functionality of these systems.

Using a LMS you can choose one from several options to customization the system according to your needs. This means that features of an LMS can be used by different user types and changed by the way they want that LMS work. You can suit features such as language options or notification settings. A LMS offers access to students wherever they are, e.g. they can access course materials from home, promoting open and flexible learning environment [1]. LMSs allow academics to post additional content at any time without limitation from class schedule. You can share your content via Facebook, Twitter, LinkedIn, etcand this implies that systems are integrated with social media. Through an LMS you can generate reportsthat can be presented graphically and to be better understood. Most LMSs have many test functionality, which are a significant part of online courses. Initially you can use some built-in templates, set a time limit for tests, set up a multiple choice test and choose to have the results displayed on screen for students. 


\section{Types of LMSs}

Tools of LMSs can be divided into three major groups and involve: Commercial LMS, OpenSource LMS and Cloud-based LMS [4].Since there are a wide variety of management systems, the selection of one of them should be done in accordance with academic needs and this should fulfill the goals and objectives of the learning process. These systems can share the same tools but each one offers a unique set of features and user interface. To evaluate each system you need to consider some criteria. You should choose the system for the purpose for which you will use it, according to your budget. You should also look at features such as: multimedia tools, communication, design, accessibility, and technical support.

If you can pay for an LMS you can choose a commercial system that will be a potential product and offer a higher level support. These LMSs have been licensed by developers. However, you should check if the features you need are included. Examples of the commercial LMSs are: Blackboard (the most known and used), Desire2Learn (D2L), ANGEL, eCollege, LearningSpace [5], etc.

By definition "Open Source LMS", the source code is available under a free public license giving users the right to use, modify, improve and adapt to their needs. Therefore we say that these systems are suitable in the higher education sector [6]. Examples of the open source LMSs are: Moodle (the present leader), Sakai, ILIAS [7], Canvas, eFront LMS, Dokeos LMS, Claroline, etc.

Cloud-based System is sometimes called Software as a Service (SaaS). It requires a tool (computer, Smartphone, tablet) and an internet connection to deliver the education online to any student, at anytime and anywhere [4]. It reduces costs in several ways: it avoids costs for infrastructure such as hardware and data servers, it reduces IT support services, eliminates paying upfront for application software licenses and decreases the cost of maintenance and supporting those applications. Examples of Cloud-based LMSs are: TalentLMS, Path LMS, Rise LMS, Firmwater LMS, LoudCloud, [5] etc.

\section{Why we choose Moodle}

Moodle is an online learning environment, build to support classroom teaching. This platform is built by experts upon the pedagogical principles. Moodle stands for Modular Object Oriented term Developmental Learning Environment and is a CMS. It is widely used by schools, universities, courses and even businesses. Moodle is considered the best platform because it offers facilities, can be best adapted and productive in education [8]. This is evidenced by the distribution rate and its use worldwide.Moodle already has a large community of users and developers around the world, where according to Moodle Statistics [9] the United States of America (USA) occupies first place. Moodle's source code is written in PHP, a common, free scripting language that was originally developed for building dynamic Web pages [10]. Some features that make this platform more enjoyable are:

-It is a free open-source, that makes it more popular than other systems;

-Itsinterfaceissimple and intuitive, both for professors and students;

-It is easy to run, administer and maintain;

-It enables: publication of course materials, task management (assignment, collection and evaluation), convenient file management, the creation of questionnaires and online tests, archives with questions, exercises and problems;

-It provides ease of communication between students and professors outside of class;

-It keeps notes of ratings, grades, absences,etc;

-You can use Moodle at any time, anywhere and in any device; 
We can add different activities, for example: assignment, chat, forum, glossary, lesson, quiz, etc or resources, for example: book, file, label, page, URL. This is shown in the picture below:

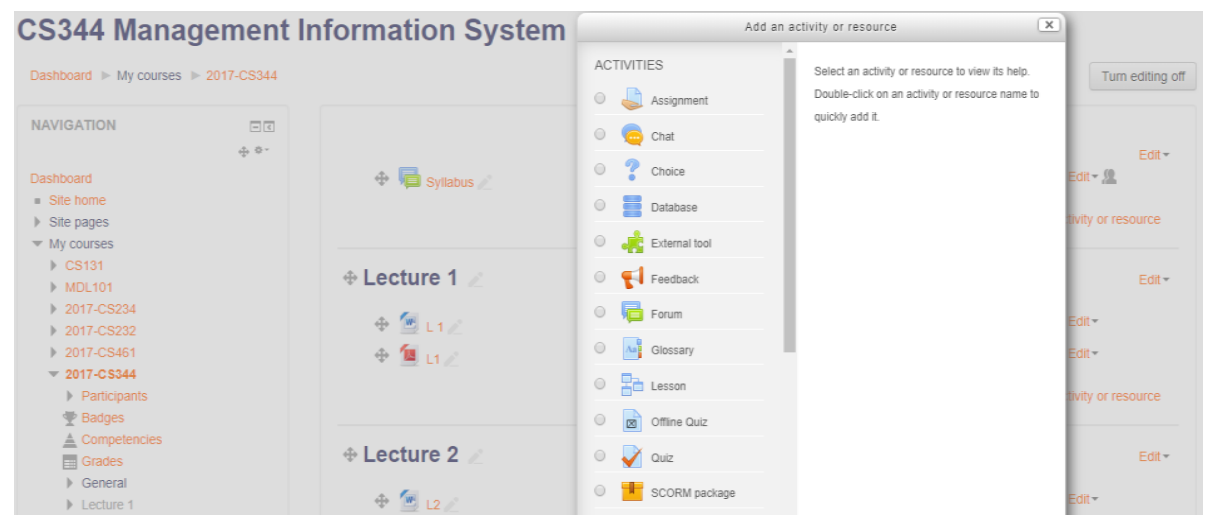

Fig. 2.Adding activities and resources

As we can see in Fig. 1, are displayed a variety of activities through which teachers can accomplish a series of learning objectives. For teachers and students this interface is easily understandable. For instance, through the assignment activity module, the teacher can post assignment, collect student work (download assignments) and provide grades.

In Fig. 2 we see how to add a new assignment. This activity has feature such as: availability, submission types, feedback types, submission settings, group submission settings, notifications, grade, etc.

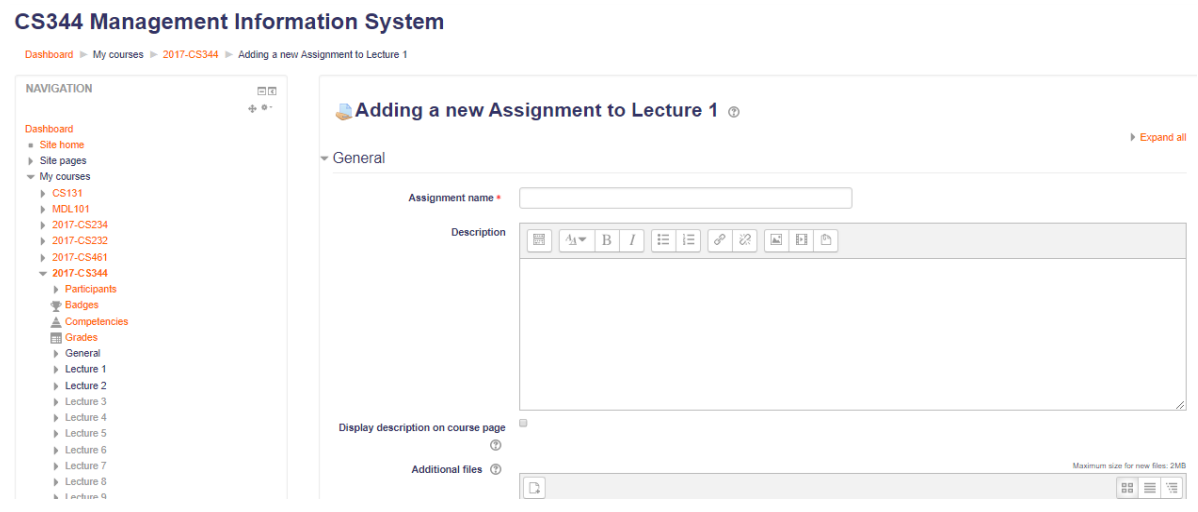

Fig. 3. Assignment Activity in Moodle

The teacher should specify all theseand then students can upload their assignments individually or as a member of a group. They can upload any file type. Final grades are recorded in the gradebook. 
Another important activity in Moodle is the creation of quizzes, as we can see below.

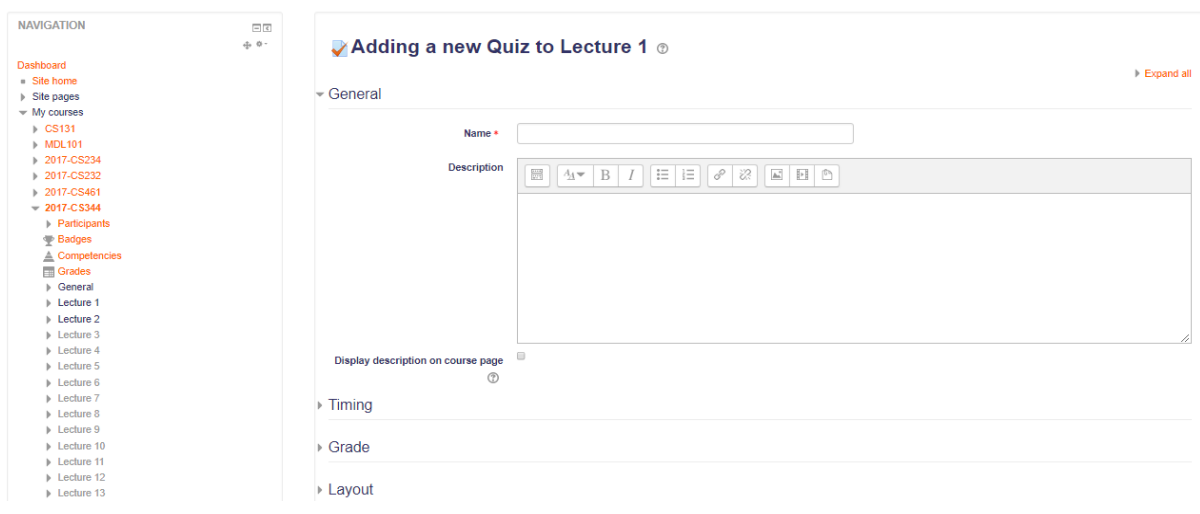

Fig. 3. Quiz Activity in Moodle

Besides the general data must be completed and feature such as: timing, question behavior, appearance, overall feedback, common module settings, etc. A teacher can create quizzes including questions of various types, e.g. multiple choice, matching, short-answer and numerical, selected from the question bank. A time limit may be set. Quizzes may be used as mini tests, as course exams, as exam practice or for self-assessment.

\section{Conclusions}

In this article we introduce a LMS, we identify three main categories of a LMS and the overall goal is to present the benefits of the most effective learning platform, Moodle. Moodle meets your needs even if you are a teacher, student or administrator. It enables the delivery of course materials, online course management and it offers the communication and collaboration tools. Moodle is a program with countless features, but also flexible, allowing you to use only features that are of interest to you or need for teaching. The selection of a flexible, efficient, helpful and productive LMS is fundamental for institutions.

\section{References}

1. Wright, C. R., Lopes, V., Montgomerie, T. C., Reju, S. A., \&Schmoller, S. Selecting a learning management system: Advice from an Academic Perspective. Educause Review. July11, 2016.

2. (CAPO.2003. Multimedia and e-learning: a new direction for productivity promotion and enhancement. Tokyo: Asian Productivity Organization. Tokyo. CAPPO.2003. ISBN: 92833-2344-0.

3. Watson William R. and Watson Sunnie Lee, - An Argument for Clarity: What are Learning Management Systems, What are They Not, and What Should They Become? |TechTrends, Volume 51, Number 2, March/April 2007. 
4. OEpignosis LLC. E-LEARNING: CONCEPTS, TRENDS, APPLICATIONS. V 1.1 January 2014. San Francisco, California, CA 94104, United States of America.

5. CEI Report. Trends and the Future of Learning Management Systems (LMSs) in Higher Education. University at Buffalo. Center for Educational Innovation.

6. T. Martin-Blas, A. Serrano-Gernandez, The role of new technologies in the learning process: Moodle as a teaching tool in Physics, Computers \& Education 52 (2009) 35-44.

7. CUE, 2003. Learning Management Systems for the Rest of Us, White Paper Open Source Learning Management Systems. A research report presented by Corporate University Enterprise, Inc, 1.May.2003.

8. Davis, B., Carmean, C., Wagner, E. D. (2009). The Evolution of the LMS: From Management to Learning. Deep Analysis of Trends Shaping the Future of e-Learning. Sage Road Solutions LLC. The eLearning GuildTM, Santa Rosa, California, USA. Accessed July 2014 at: http://www.blackboard.com/resources/proed/guild-lmsreport.pdf.

9. Moodle Statistics. Moodle.net Courses \& Content Web page. Accessed 31st of August 2014 at: http://moodle.net/stats/.

10.Monarch Media Inc. Business white paper open-source learning management systems:Sakai and Moodle, 2010. www.Monarchmedia.com. 